\title{
High-cycle fatigue strength of a pultruded composite material
}

\author{
C. Colombo, M.Guagliano, L. Vergani \\ Dip.to di Meccanica, Politecnico di Milano, Via La Masa, 1 - 20156 Milano Italy
}

RIASSUNTO. I compositi pultrusi sono tra i più attraenti materiali per applicazioni che richiedono produzione su grande scala. Per questo motivo il loro impiego nell'ambito di applicazioni strutturali è in continuo aumento, anche se ancora limitato da una incompleta conoscenza del loro comportamento a fatica. La maggior parte dei dati a disposizione si riferisce, infatti, a prove interrotte dopo 3 milioni di cicli.

In questa memoria si considera un pultruso utilizzato in ambito strutturale e si caratterizza il suo comportamento statico e a fatica. I risultati hanno permesso di ricavare le curve S-N del materiale e di verificare l'esistenza del limite di fatica. Le osservazioni condotte al SEM hanno consentito di valutare i meccanismi di danneggiamento che si verificano durante il cedimento statico e a fatica.

ABSTRACT. Dealing with composites in polymeric matrix, the pultruded ones are among the more suitable for large production rates and volumes. For this reason, their use is increasing also in structural applications in civil and mechanical engineering.

However, their use is still limited by the partial knowledge of their fatigue behaviour; in many applications it is, indeed, required a duration of many millions of cycles, while most of the data that can be found in literature refer to a maximum number of cycles equal to 3 millions. In this paper a pultruded composite used for manufacturing structural beams is considered and its mechanical behaviour characterized by means of static and high-cycle fatigue tests. The results allowed to determine the S-N curve of the material and to assess the existence of a fatigue limit. Observations at the scanning electronic microscope (SEM) allowed to evaluate the damage mechanisms involved in the static and fatigue failure of the material.

KEYwORDS. Delamination; pultruded composites; DGM-XGM failure; fatigue damage.

\section{INTRODUCTION}

$\mathrm{P}$ ultrusion is one of the most attractive technological process for obtaining polymer matrix composite parts to be manufactured with large production rates and volumes [1-3]. Due to this characteristic and to some peculiar aspect of their physical and mechanical behaviour, pultruded composite are getting more and more used in structural applications in civil infrastructures. This is due to the progress made in pultrusion technology, that allows the capability to manufacture low-cost large-scale load carrying structural profiles. If the fact that these materials do not need painting, that they do not conduct electricity (thus, not needing to be insulated) and that, thanks to lightness, they use allows to reduce transportation costs and environmental pollution, it seems clear why they are becoming a serious alternative to metal alloys for the construction of shaped beams, pedestrian bridge decks, post for railway noise barriers, floors of bus and other structural parts [4-6].

However, their application in structural engineering is still somewhat limited by the incomplete knowledge about the fatigue strength, that is to say that the behaviour of pultruded composite under time variable loads is not completely investigated and understood. In fact, there are few data that can be found in the references. In [7] a comparative study between the fatigue behaviour of GRP hand lay-up and pultruded phenolic composites is described, but the maximum number of cycle of interest is limited to 1 million, thus preventing the application of these data to longer life-span, typical of civil infrastructures. In [8] the long-term environmental fatigue behaviour of pultruded glass-fiber-reinforced 
composites under flexural loading is investigated, while [9] describes the tensile fatigue performances of pultruded reinforced polymers profiles, with particular emphasis on the effect of the specimens shape on the fatigue strength and endurance. In the same paper some results obtained from fatigue tests up to 10 million cycles are reported, but the results number is limited and does not allow the determination of a fatigue limit. In [10] the rotating bending fatigue strength of a pultruded glass fiber reinforced composite is investigated.

In [11] the residual fatigue strength of a pultruded composite after damage occurred due to impact of a external object is considered.

Other papers focus their attention on pultruded composite application in fatigue loaded parts. In [12] the fatigue performance of a cellular FRP bridge deck adhesively bolted to steel girders is investigated, while in [13] the fatigue strength of a pultruded I-shaped post for railway noise barriers is considered and analyzed by means of ad-hoc experimental tests.

From the analysis of references, it is clear that the designer cannot found sufficient data and knowledge for a safe and reliable application of pultruded materials for structural applications where a long life (many millions of cycles) is required. Only a couple of papers report data for such a long endurance and the number of specimens under investigations is limited and further research is needed, both for obtaining quantitative data and to know much about the failure mechanisms by changing the load amplitude. This paper intends to give a contribution in this field. A glass fiber reinforced composite obtained by pultrusion and used for box shaped beams used in civil infrastructures (i.e.: noise barriers, [6]) is considered and experimentally analyzed. Its static behaviour is investigated by means of tensile tests while the observations at the scanning electronic microscope allowed to investigate the damage mechanism involved in the static failure.

Then the fatigue behaviour of the material was investigated by means of axial tests ( $R=-1)$ long up to 10 million cycles. The results showed a narrow scatter and allowed to determine the S-N curve and to assess the existence of the fatigue limit. By means of the SEM analysis it was moreover possible to understand how fatigue damage develops in the different layers of materials.

\section{MATERIAL}

he material is a glass-fiber reinforced composite obtained by pultrusion. The matrix is made of equally distributed polyester not saturated resins commercially called Leguval W 24 GA and Synolite 0175-N-1. The global volumic mass of the matrix is about $1,3 \mathrm{~g} / \mathrm{cm}^{3}$. The E glass fibers have a ultimate tensile strength of $1800 \mathrm{MPa}$, an elastic modulus of $76 \mathrm{GPa}$ and a volumic mass of $2.53 \mathrm{~g} / \mathrm{cm}^{3}$.

In Fig. 1 it is shown the section from which the specimens were cut: these latter were obtained from the longer side. In the same figure it is shown the the lay-up of the material and different layers can be observed: their composition is described in Tab. 1. It can be noted that most of glass fibers (84\%) are unidirectional (Roving) while the remaining part $(16 \%)$ is randomly distributed.

Sontara is a thin layer used on the surface to prevent surface damage due to impacts or to the aggressive environment effects. Reemay is a surface writing. Both Sontara and Reemay does not modify mass and mechanical characteristics of the material.

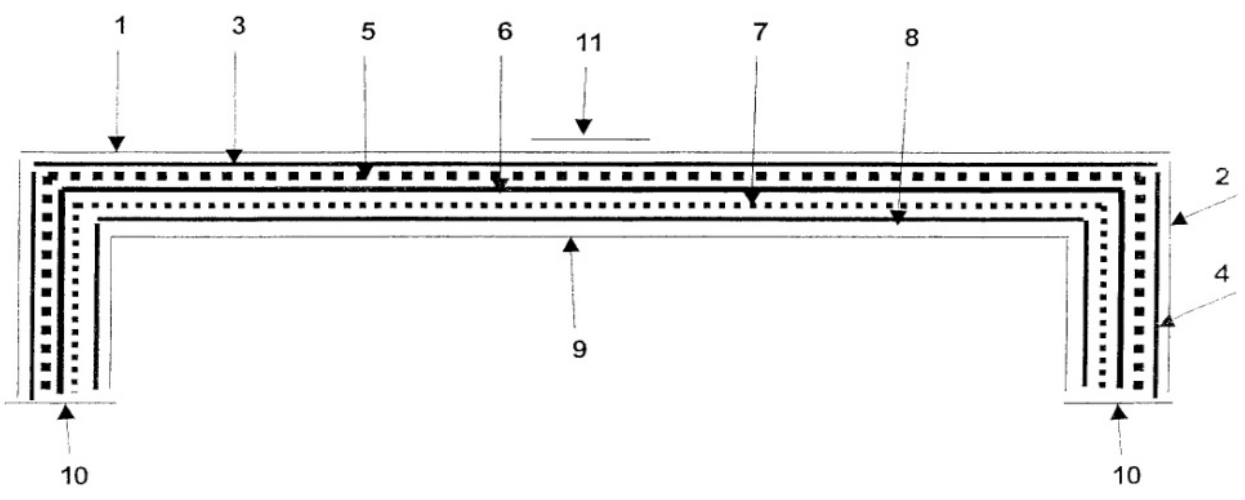

Figure 1: Section of the pultruded bar from which the specimens were cut. 


\begin{tabular}{|c|c|c|c|c|c|}
\hline Position & Width (cm) & Material & $\begin{array}{l}\text { Mass per unit } \\
\text { length }(\mathrm{g} / \mathrm{m})\end{array}$ & $\begin{array}{l}\text { Roving mass per } \\
\text { unit length } \\
(\mathrm{g} / \mathrm{m})\end{array}$ & Weight $\%$ \\
\hline 1 & 17 & SONTARA & 5.95 & & \\
\hline 2 & 6 & SONTARA & 4.2 & & \\
\hline 3 & 16 & MAT & 48 & & \\
\hline 4 & 5 & MAT & 30 & & \\
\hline 5 & & ROVING & & 960 & \\
\hline 6 & 21 & VOLUMAT & 126 & & \\
\hline 7 & & ROVING & & 547.2 & \\
\hline 8 & 21 & MAT & 63 & & \\
\hline 9 & 23 & SONTARA & 8.05 & & \\
\hline 10 & 5 & SONTARA & 3.5 & & \\
\hline \multirow[t]{6}{*}{11} & 4 & REEMAY & 0.8 & & \\
\hline & & Total woven & 289 & & 16 \\
\hline & & Total roving & & 1507 & 84 \\
\hline & & & Total resin & 1796 & 57 \\
\hline & & & Total glass & 1354 & 43 \\
\hline & & & Total weight & 3150 & 100 \\
\hline
\end{tabular}

Table 1: Chemical composition of the layers of the pultruded material (the position refers to Fig. 1).

In Fig.2 it is shown a micrograph of the transversal section taken at the SEM showing the main layers of the material. From the SEM observation it was possible to effectively define the layer disposition in a section (Fig. 3).

In Fig. 4 the SEM micrographs of these layer is shown. It can be noted that the fibers in the Roving are nearly aligned, equal-spaced and parallel. Also the different fiber percentages of Mat and Volumat can be noted.

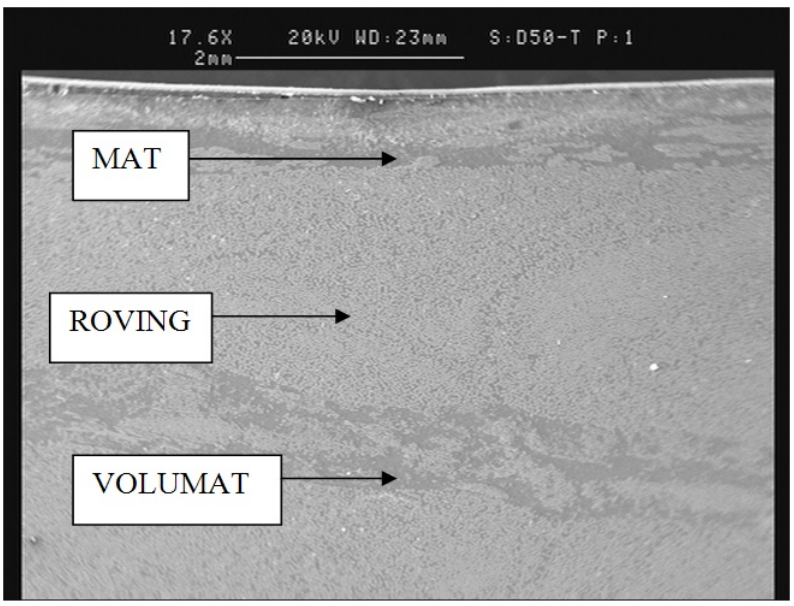

Figure 2: SEM micrograph showing Mat, Roving and Volumat layers. 


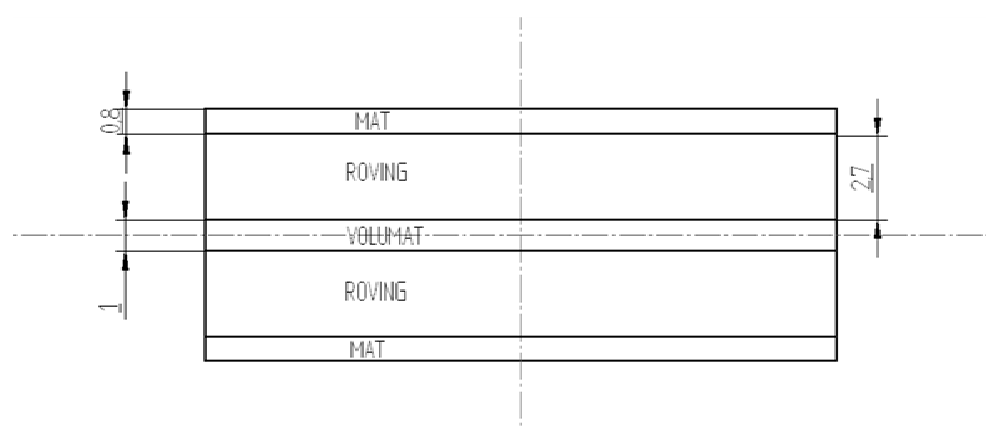

Figure 3: Layer disposition in a generic section of the samples.

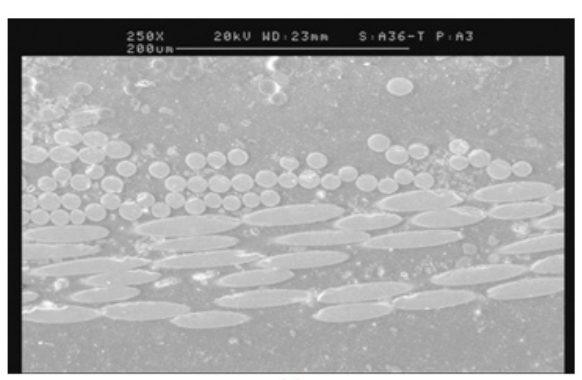

(a)

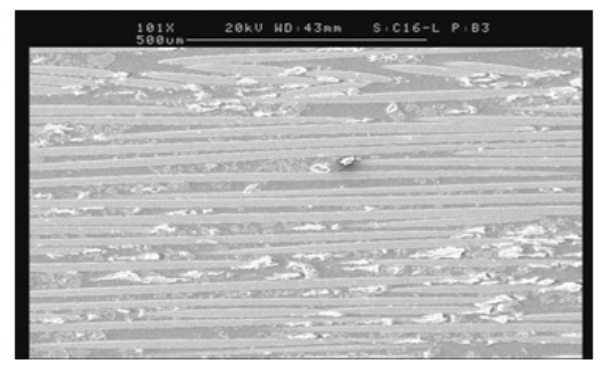

(b)

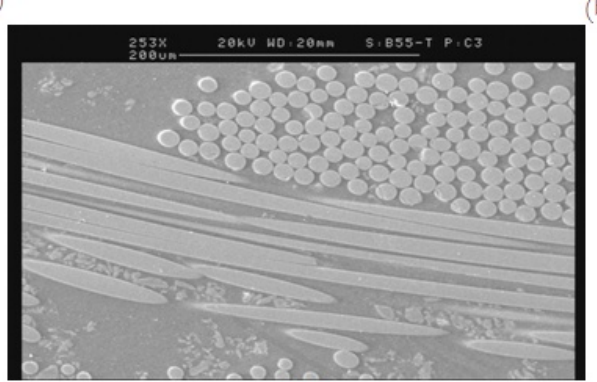

(c)

Figure 4: SEM micrographs of Mat (a), Roving (b) and Volumat (c) layers.

\section{STATIC CHARACTERIZATION}

1

he static behaviour characterization of the pultruded material was obtained by means of tensile and compression tests. Five samples for each kind of test were executed by using a Schenck Hydropuls 250kN universal test machine. The tensile tests were executed according the ASTM D 3039/D 3039 M-00 standard, while as regards the compression tests the EN ISO 527-5: 1997 standard was applied. The specimens were cut along the longitudinal direction and presented a rectangular constant cross section, as indicated in the standards that were used. The same sample type was used in both the tensile tests and the compression ones; in Fig. 5 their dimensions are shown together with the aluminium grips that were glued to the specimens. An extensometer was applied to measure the deformation of the specimens.
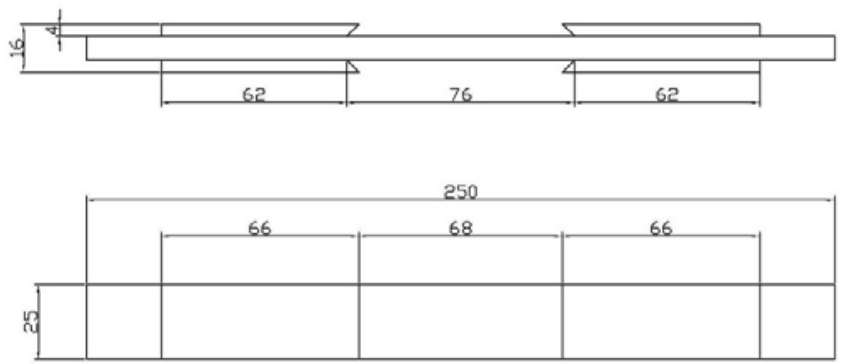

Figure 5: Shape and dimensions in $\mathrm{mm}$ of the samples used in the static tests. 
In Tab. 2 the results of the tests are shown.

In Fig. 6 the typical aspect of a DGM failure is shown.

Some interrupted tensile and compressive tests were also executed, being the aim to investigate the development of the damage by means of observations at the SEM. These analyses allowed to assess the progressive nature of damage in the different layers of material. In particular cracks between the fibers and the matrix were observed with increasing length with the load, while their number remained about the same till the final rupture. However some broken fibers were noted in the Roving layer for high values of the stresses. In Fig. 7 some SEM images showing the damage evolution are shown: Figs $7 \mathrm{a}$ and $7 \mathrm{~b}$ show the damage evolution in the Mat at $200 \mathrm{MPa}$ and $340 \mathrm{MPa}$ : the interface crack evolution between the matrix and the fibers can be easily observed. Figs $7 \mathrm{c}$ and $7 \mathrm{~d}$ show the Roving and also in this case the most evident damage type is the formation of interface cracks.

\begin{tabular}{ccccccc}
\cline { 2 - 5 } & Specimen & E $(\mathrm{MPa})$ & UTS $(\mathrm{MPa})$ & $\begin{array}{c}\text { Elongation } \\
\%\end{array}$ & Failure type & Failure zone \\
\multirow{3}{*}{ Tensile } & 1 & 30605 & 367 & 1,20 & DGM & Middle \\
& 2 & 30794 & 377 & 1,23 & DGM & Middle \\
\multirow{3}{*}{ tests } & 3 & 31005 & 377 & 1,21 & DGM & Middle \\
& 4 & 30003 & 361 & 1,20 & DGM & Middle \\
& 5 & 28791 & 381 & 1,32 & XGM & Middle \\
& Mean & 30240 & 373 & 1,23 & & \\
\hline
\end{tabular}

\begin{tabular}{ccccccc} 
& Specimen & E $(\mathrm{MPa})$ & UCS $(\mathrm{MPa})$ & $\begin{array}{c}\text { Elongation } \\
\%\end{array}$ & Failure type & Failure zone \\
& 1 & 31311 & 454 & 1,45 & DGM & Middle \\
\multirow{2}{*}{ Compres- } & 2 & 27296 & 383 & 1,40 & DGM & Middle \\
\multirow{2}{*}{ sion } & 3 & 26607 & 382 & 1,43 & DGM & Middle \\
tests & 4 & 26973 & 375 & 1,39 & DGM & Middle \\
& 5 & 31313 & 402 & 1,28 & DGM & Middle \\
& Mean & 28700 & 399 & 1,39 & & \\
\cline { 2 - 7 } & value & \multicolumn{7}{c}{ Table 2: Summary of the results of the static tests }
\end{tabular}

(DGM= edge Delamination Gage Middle, XGM=eXplosive Gage Middle)

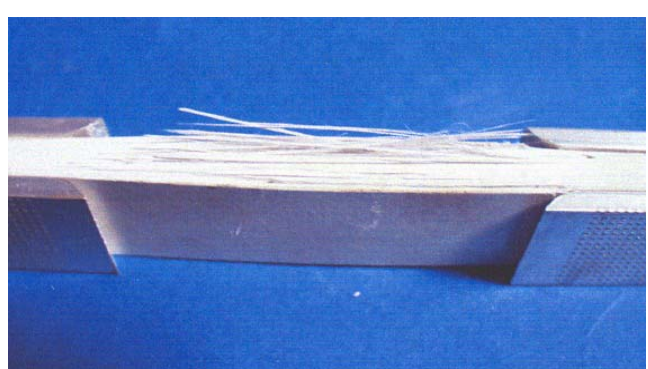

(a)

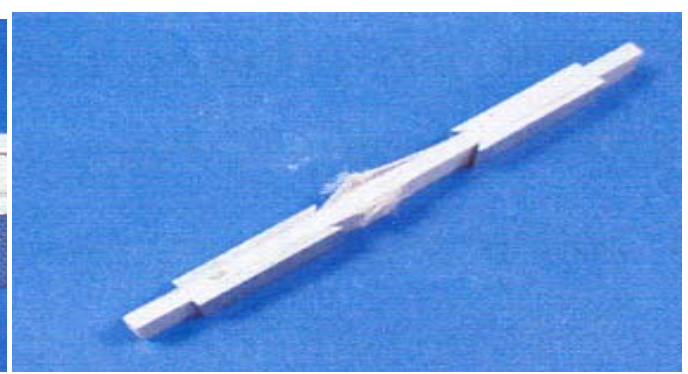

(b)

Figure 6: Typical aspect of a DGM failure: (a) tensile failure, (b) compression failure.

Similar observations performed on compression specimens evidenced the same damage evolution.

\section{FATIGUE CHARACTERIZATION}

\footnotetext{
A xial fatigue tests $(\mathrm{R}=-1)$ were executed, being the aim the determination of the $\mathrm{S}-\mathrm{N}$ curve of the material and to verify the existence of a fatigue limit. The specimens have constant section and their geometry is the same as in Fig.5. The specimens were considered run-out if failure did not occur till 10.000.000 cycles. Tests were performed in loop load control and the imposed frequency was $5 \mathrm{~Hz}$; no temperature increment was observed. Fifteen specimens were used to determine the fatigue limit according the stair-case procedure while other nine specimens were tested to determine the leaning part of the S-N curve according to the procedure included in the ASTM E 739-91. In Fig. 8 the results are shown: it is possible to observe the limited dispersion of the data. If the applied stress decrease from $120 \mathrm{MPa}$
} 
to $80 \mathrm{MPa}$, the endurance passes from around 550.000 cycles to more than 10 millions cycles (run-out tests). It can be deduced that this material has a fatigue limit and, according to the stair case method, its value was calculated as $90 \mathrm{MPa}$.

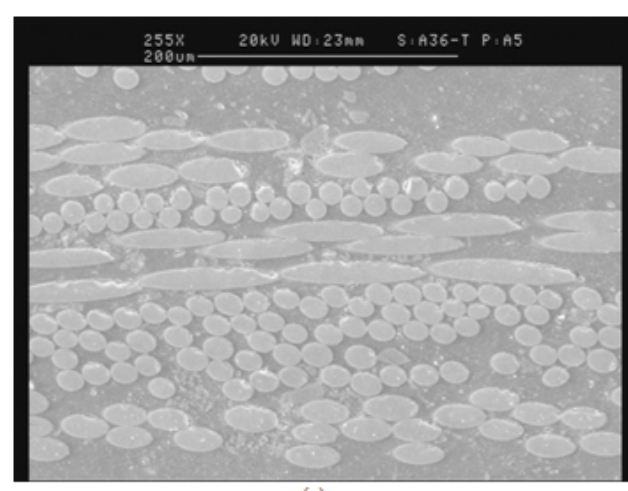

(a)

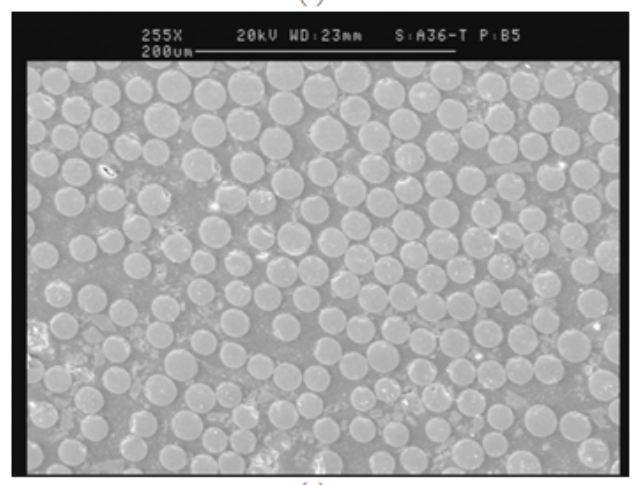

(c)

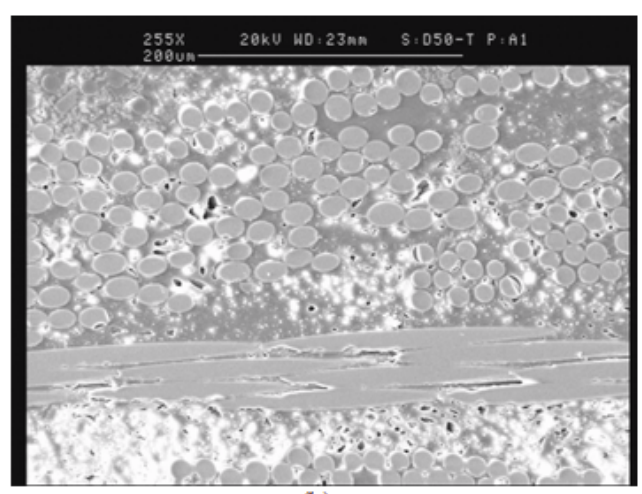

(b)

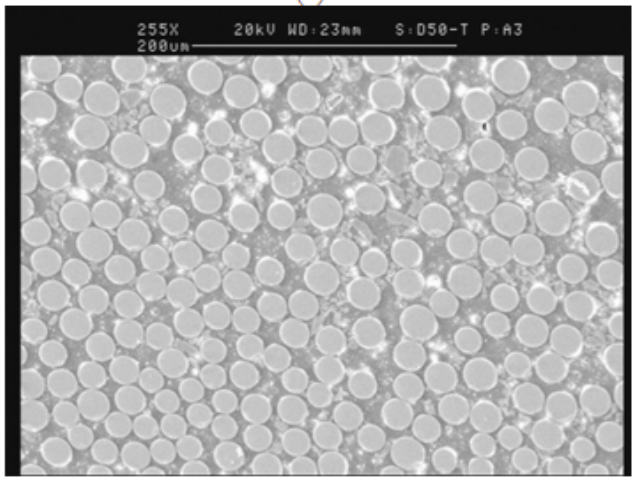

(d)

Figure 7: Damage evolution for increasing stress values (transversal section):

(a) Mat $200 \mathrm{MPa}$, (b) Mat $340 \mathrm{MPa}$, (c) Roving $200 \mathrm{MPa}$, (d) Roving $340 \mathrm{MPa}$.

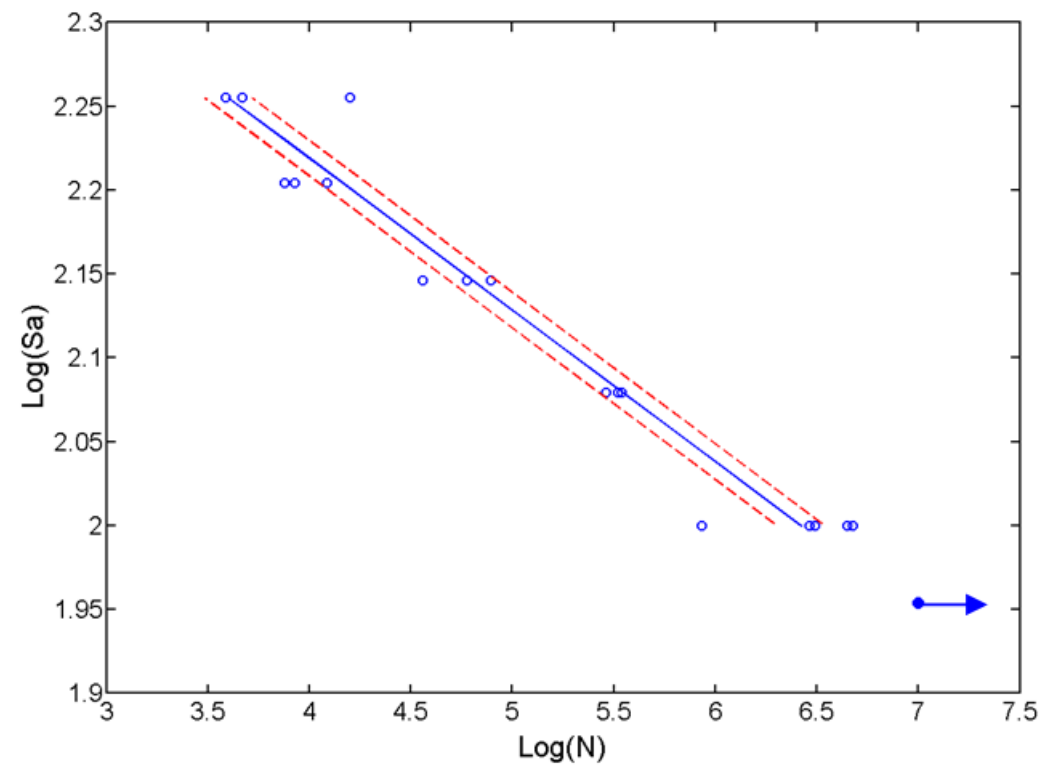

Figure 8: Experimentally determined S-N curve of the pultruded material.

( $\bigcirc$ : broken specimens; $\bullet$ : fatigue limit; - maximum likelihood estimation for the mean, --- confidence limits for the model at $95 \%$ )

Most of the failures happened near the gripping zone, like in Fig. 9; this denotes a probable influence of the gripping system onto the obtained results and it is in agreement with the results reported in [9] where the influence of the specimens shape was analysed and where it is found that this kind of specimens gives the lowest fatigue strength. 


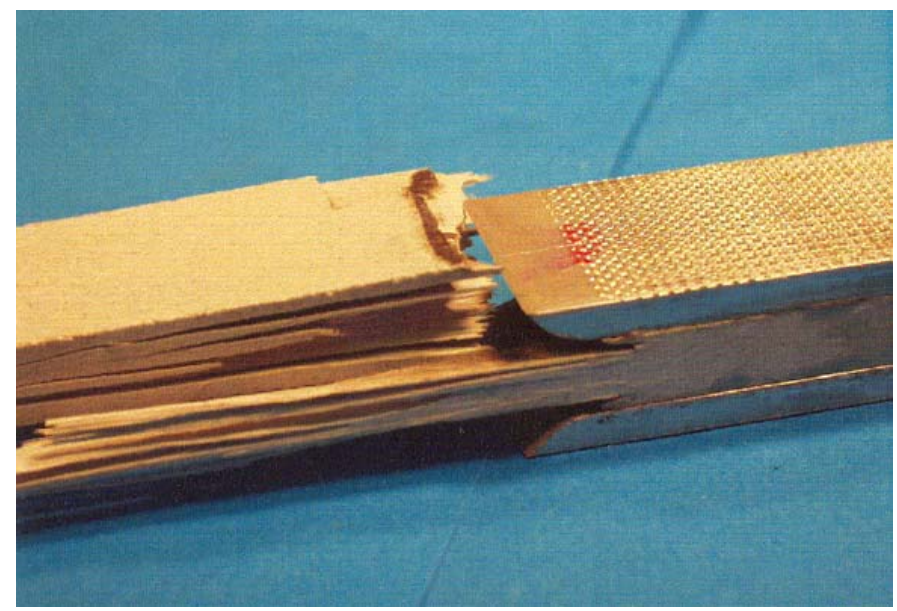

Figure 9: A fatigue broken specimen near the gripping zone.

Also in this case SEM observations have been performed on run-out specimens to evaluate the fatigue damage. Pictures showing SEM images after 10 millions cycles are reported in Fig. 10, that refers to longitudinal sections: the presence of arrested cracks can be noted.

On the basis of the analysis of SEM observation a quantitative estimation of the fatigue damage was made by counting the number of different defects in the layer that form the pultruded material. The results are shown in Tab. 3 and evidence that debonding (crack between matrix and fibers) in the Mat layer is the main responsible of the fatigue damage of this material

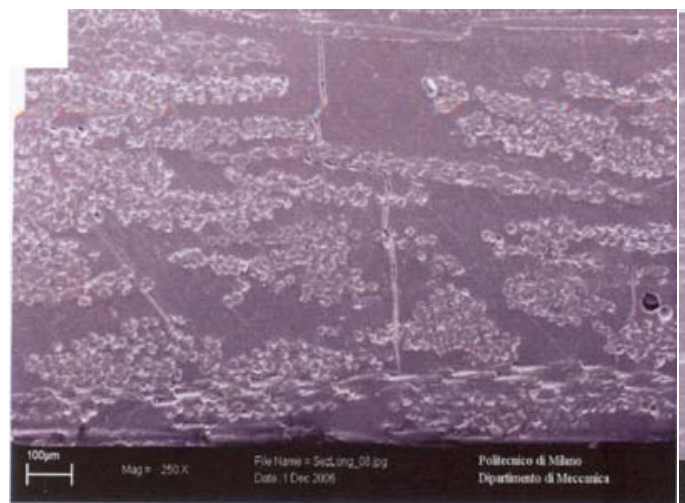

(a)

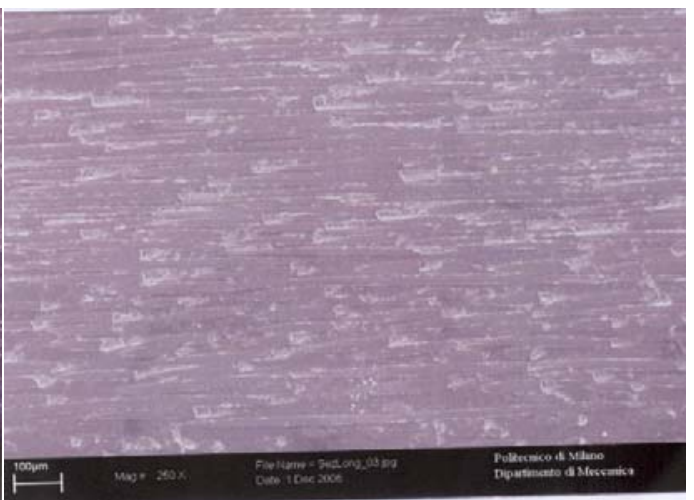

(b)

Figure 10: SEM images of the fatigue specimens: (a) Mat, (b) Roving.

\begin{tabular}{cccc}
\hline & Mat & Roving & Volumat \\
Debonding & 67 & 25 & 60 \\
Fiber Cracks & 30 & 15 & 8 \\
Matrix cracks & 5 & 0 & 0 \\
\hline
\end{tabular}

Table 3: Defect count in the fatigued run-out specimens

\section{CONCLUSIONS}

7 he static and fatigue behaviour of a pultruded glass-fiber reinforced composite material used in structural applications was investigated. On the basis of the tests executed it was possible to determine quantitative data that can be applied for the design of structural parts manufactured with this material. The fatigue tests allowed to determine that the material has a fatigue limit that can be used for designing long life-span parts subjected to time variable loading. The SEM observation allowed to evidence the evolution of static and fatigue damage. In particular, as regards this latter one, it was possible to assess that fatigue damage take place mainly in the Mat layer and that it mainly consists in 
deboning, that is to say it consist in the initiation and propagation of cracks at the interface between the polymer matrix and the glass fibers.

\section{ACKNOWLEDGEMENT}

This research was founded by the grant "Damage analysis of composite materials under fatigue loading" (MIUR - PRIN 2007).

\section{REFERENCES}

[1] F.S. Trevor, Pultrusion for Engineers, CRC Press, Woodhead Publishing, Ltd, Cambridge (2000).

[2] B.T. Åmström, Manufacturing of Polymer Composites, Chapman \& Hall, London (1997).

[3] J.P. Fanucci et al., Pultrusion of Composites, in: T.G. Gutowski (Ed.), Advanced Composites Manufacturing, J. Wiley \& Sons, New York, (1997) 259-295.

[4] L.-H. Gan, L. Ye, Y.-W. Mai, Composite Structures, 45 (1999) 279-288.

[5] A. Di Tommaso, S. Russo, Mechanics of Composite Materials 39 (4) (2003) 329-340.

[6] M. Guagliano, Fatigue behaviour of a pultruded composite box-shaped post for high speed railway application (in Italian), Internal Report 48/2004, Politecnico di Milano.

[7] C. Moura Branco et al., Int. J. Fatigue, 18 (4) (1995) 255-263.

[8] K. Liao, C.R. Schultheisz, D.L. Hunston, Int. J. Fatigue 21, (1999) 485-495.

[9] T. Keler, T. Tirelli, A. Zhou, Composite Structures, 68 (2005) 235-245.

[10] L. Vergani, Damage mechanisms in pultruded unidirectional fiber reinforced composites under static and fatigue loads, in: M.Guagliano, M.H. Aliabadi (Eds.), Fracture and Damage of Composites, WIT Press, Southampton, 206 (2006) 49-72.

[11] T.J. Chotard, J. Pasquiet, M.L. Benzeggagh, Composite Structures, 53 (201) 317-331.

[12] T. Keller, H. Gürtler, Composite Structures, 70 (2005) 484-496.

[13] T. Keller, F. Riebel, T. Vallée, Composites Structures, 85 (2008) 116-125. 